\title{
ANALISIS SUMBER DAYA MANUSIA (SDM) PT. WEHA TRANSPORTASI INDONESIA Tbk.
}

\author{
Nur Wildan Mubarok ${ }^{1}$, Nurdayanti ${ }^{2}$, Nurul Fadliyah Hidayatunisa ${ }^{3}$, \\ Nurul Rahayu ${ }^{4}$, Nyimas Laeli Nurbayanti ${ }^{5}$ \\ 1,2,3,4,5 Universitas Islam Negeri Sunan Gunung Djati, Bandung \\ Email:wmubarok24@gmail.com
}

\begin{abstract}
Abstrak
Penelitian berdasarkan data-data ini bertujuan untuk menganalisis sumber daya manusia PT.WEHA Tranportasi Indonesia Tbk, selama periode 20172018 untuk melihat kemampuan perusahaan dalam menjalankan dan mengatur sumber daya manusia. Penelitian ini menggunakan data sekunder dengan melihat laporan annual perusahaan tahun 2017- 2018 yang meliputi aspek-aspek sumber daya manusia yaitu Job description \& Job specification, recruitment and selection process, placement of staff, compentatin implementation, training and development, performance, appraissial, organization cultural and integration ( motivasi). Dalam penelitian ini menggunakan metode kualitatif sebagai metode penelitian positivme yang dapat diartikan metode penelitian kualitatif adalah dengan menggunakan logika induktif. Berdasarkan hasil penelitian ini PT.WEHA Transportasi Indonesia Tbk, menunjukan bahwa perusahaan memiliki empat pilar sumber daya manusia yang terdiri dari Rekrutmen, Renumerasi, Punishment \& Rewards , Pengembangan Dan Tahapan Karir .
\end{abstract}

Kata kunci : Rekrutment; Renumerasi; Punishment; rewards; WEHA

\begin{abstract}
Research based on these data aims to analyze the human resources of PT.WEHA Transportasi Indonesia Tbk, during the 2017-2018 period to see the company's ability to run and manage human resources. This study uses secondary data by looking at the company's annual report for 2017-2018 which includes aspects of human resources, i.e Job description \& Job specification, recruitment and selection process, placement of staff, compentatin implementation, training and development, performance, appraissial, organization cultural and integration (motivation). In this study using qualitative methods as a positivme research method that can be interpreted as qualitative research methods is to use inductive logic. Based on the results of this study PT.WEHA Transportation Indonesia Tbk, shows that the company has four pillars of human resources consisting of Recruitment, Remuneration, Punishment \& Rewards, Development and Career Stages
\end{abstract}

Keywords: Recruitment; Remuneration; Punishment; rewards; WEHA 


\section{A. PENDAHULUAN}

Sumber daya manusia merupakan salah satu faktor yang sangat penting dalam sebuah perusahaan demi mencapai tujuan dan sasaran karena sumberdaya menusia merupakan salah satu faktor penentu berhasil atau tidakmya perusahaan dalam mencapai tujuannya tersebut.Manajemen sumber daya manusia adalah proses menangani masalah pada ruang lingkup karyawan, pegawai dan tenaga kerja lainnya untuk menunjang aktivitas perusahaan untuk mencapai tujuan yang sudah di tentukan.

Cara melihat perkembangan perusahaan salah satunya dapat dilihat dari penilaian kinerja, sasaran yang menjadi objek penilaian kerja adalah kemampuan karyawan dalam melaksanakan suatu pekerjaan atau tugas yang di evaluasi denga tolak ukur tertentu dan dilakukan secra berkala. Berbagai cara untuk meningkatkan kinerja karyawan merupakan tantangan manajemen karena keberhasilan untuk mencapai suatu tujuan perusahaan tergantung pada kualitas kinerja sumberdaya manusia yang ada di dalamnya (syamsuddinnor 2014). Adapun penilaian kinerja yang dapat dilihat melalui Rekrutmen, Renumerasi, Punishment \& Rewards, Pengembangan Dan Tahapan Karir.

Rekrutment adalah proses menarik atau memilih orang yang memenuhi syarat pekerjaan. Setiap perusahaan pastinya akan melaksanakan rekrutment ini dalam perusahaannya dengan cara menyeleksi calon pekkerja dan menempatkkan di posisi kerja yang sesuai. Maka perusahaan akan mendapatkan keuntungan dari proses seleksi yang profesional.

Renumerasi adalah pemeberian gaji atau imbalan tambahan kepada seorang karyawan sebagai bentuk apresiasi atas pekerjaan atau kontribusi yang dilakukan serta sifatnya rutin kepada perusahaan dengan berbagai macam tujuan seperti untuk momotivasi karyawan agar mengembangkan diri dan menjadikan SDM yang berkualitas, mensejahterakan karyawan dan lain-lain. Dan oleh sebab itu perusahaan menerapkan punishment dan rewads terhadap karyawan. Punishment dan rewards adalah bentk penilaian atas pekerjaan yang di lakukan oleh karyawan demi meningkatkan kinerja dan kedisiplinan karyawan dalam perusahaan. 
Dalam perjalanan sejarahnya, PT. WEHA Transportasi telah melalui berbagai dinamika bisnis melalui beberapa perubahan yakni jenis armada sampai nama perusahaan. Perusahaan ini menyediakan berbagai layanan trasportasi darat dengan segmen pasar di bidang angkutan penumpang parawisata dengam meliputi kegiatan usaha menggunakan brand White Horse Delixe Coach (WHD), exsecutive shuttle jakartaBandung dan lainnya yang trediri dari pengurusa ijin kendaraan angkutan online dan perjalanan wisata domesti.

\section{B. METODE ANALISIS}

Penelitian ini dilakukan di PT WEHA Transportasi Indonesia Tbk yang beralamat di Graha White Horse. Jalan Tanjung Selor no 17 Jakarta Pusat 10150. Metode pengumpulan data di lakuakan dalam penelitian ini dengan dokumentasi untuk memperoleh informasi dengan cara melihat datadata yang terdapat dalam dokumentasi-dokumentasi tempat usaha yang diperoleh dari internet dari website http://Whitehorse.co.id/ diakses tanggal 20 Juni 2019 pukul 15.00. Metode penelitian ini merupakan cara ilmiah untuk mendapatkan data dengan tujuan dan kegunaan tertentu. Sugiyono (2015). Menjelaskan bahwa metode penelitian kuantitatif sebagai metode penelitian positivme yang dapat diartikan metode penelitian kualitatif adalah dengan menggunakan logika induktif. Penelitian kualitatif bertujuan untuk mendeskripsikan suatu fenomena sosial. Kemudian dengan menggunakan kepustakaan untuk memperoleh data sekunder, hasil penelitian terdahulu, maupun literature lainnya yang berhubungan dengan penelitian yang dilakukan saat ini. Jangkauan penelitian ini dilakuakn di PT WEHA Transportasi Indonesia Tbk, dengan website, Https://www.whitehorsegroup.co.id. dan di khususkan pada masalah yang berhubungan dengan aspek sumber daya manusia analisis yang terkait Job description \& Job specification, recruitment and selection process, placement of staff, compentatin implementation, training and development, performance, appraissial, organization cultural and integration ( motivasi) ditinjau terdiri dari Rekrutmen ,Renumerasi Punishment \& Rewards , Pengembangan Dan Tahapan Karir dan analisis priode 2017 - sampai tahun 
2018. Rincian data yang diperlukan untuk memperoleh gambaran yang jelas tentang masalah dan pemecahan serta mempermudah pembahasan maka data-data yang diperlukan untuk melengkapi tujuan penulis ini adalah kondisi atau gambaran umum PT WEHA Transportasi Indonesia Tbk, stuktur organisasi, visi misi perusahaan dan lain-lainnya.

\section{HASIL DAN PEMBAHASAN}

Sumber Daya Manusia PT WEHA Transportasi Indonesia, Tbk menitik beratkan pada pengembangan Sumber Daya Manusia untuk mendapatkan kepuasan pelanggan. Oleh karena itu, mulai dari bagian yang berhubungan langsung dengan pelanggan yakni pengemudi, mitra, call center, Sales Counter, dispatceh, Customer Care sampai dengan bagian yang berfungsi sebagai pendukung berjalannya operasi seperti bagian Tekhnikal, Keuangan, Operasi, Teknologi, Informasi, dan Human Resources. Fokus perusahaan tidak hanya kepada bagian yang berhubungan langsung dengan pelanggan, namun juga memfokuskan pada bagian pendukung pelayanan untuk pelanggan.

Berikut 4 pilar Manajemen Manusia PT. WEHA Trasportasi Indonesia Tbk:

\section{Rekrutmen}

Prosesnya berasaskan kepada keterbukaan serta menghormati nilainilai kemanusiaan, dengan berpijak pada Visi, Misi, Nilai serta Panduan Perilaku Pelayanan yang seirama dengan budaya perseroan. Dalam proses rekrutmen tersebut akan terpilih sumber daya manusia yang kompetitif di masyarakat dengan cara penyeleksian yang ketat dengan serangkaian tek psikologi guna melihat karakter yang sesuai dengan budaya perseroan dan berpegang pada kriteria kompetensi yang dibutuhkan untuk memangku jabatan tertentu. Khusus untuk pengemudi dan mitra, tes tersebut meliputi kemampuan memberikan pelayanan prima, kemampuan bahasa asing, pengetahuan mengenai ibu kota dan sekitarnya, serta kemampuan mengemudi dengan nyaman dan aman.

\section{Renumerasi}


Penerapan renumerasi perusahaan dilandaskan atas dasar produktivitas dan performa tanpa mengindahkan aturan pemerintah atas kebijakan minimum renumerasi. Dengan demikian renumerasi tidah hanya terdiri dari upah pokok berdasarkan Upah Minimum Kabupaten/Provinsi, namun juga berdasarkan insentif yang sifatnya berjenjang, atas performa kerja, dan komisi untuk mitra. Perseroan kemudian terus memonitor produktifitas kerja, untuk mencapai sasaran mutu perbagian, hingga ke masing-masing individu. Hal demikian dilakukan agar sesuai dengan system manajemen mutu yang diterapakan perseroan yakni ISO 9001:2008.

\section{Punishment and Rewards}

Dasar diberlakukannya Punishment dan Rewards, ialah untuk menjaga budaya perseroan serta memberikan dorongan untuk menciptakan budaya sesuai nilai yang dijungjung tinggi.

Oleh karena itu, perseroan merancang strategi serta rencana aksi yang terintegrasi dengan:

a. Hubungan kerja antara karyawan, mitra serta perseroan yang jelas tertuang kedalam perjanjian kemitraan serta kontrak kerja yang legal, atas persetujuan kedua belah pihak serta memuat hak dan kewajiban masing-masing.

b. Sosialisasi dilakukan sejak karyawan masuk kerja, dan terus lewat memo-memo internal, majalah, dan dinding.

c. Membangun serangkaian "do and donts" yang aplikatif, disertai sosialisasi aturan perusahaan yang berlaku.

d. Punishment dirancang melalui penerapan sanksi yang segera dan jelas.

e. Reward diberikan kepada pengemudi terbaik White Horse, Kenek terbaik White Horse, dan mitra yang mencapai argo terbaik baik bulanan maupun tahunan.

f. Penguatan budaya perusahaan lewat media internal seperti majalah internal perusahaan yang berisikan kisah inspiratif yang nyata dialami oleh karyawan serta mitra dalam kehidupan pekerjaan sehari-hari

\section{Pengembangan dan Tahapan Karir}


Dasar dari pengembangan terhadap manusia yakni membangun manusia yang memiliki nilai serta perilaku perseroan yang dapat memberikan performa maksimal dalam kinerjanya. Untuk mendukung performa tersebut, maka diberikan pelatihan terhadap sikap kerja, pelatihan pemahaman terhadap pekerjaannya sendiri serta kontribusi individu tersebut terhadap kinerja bagian maupun pada perseroan. Serangkaian program pengembangan dimulai dari pelatihan dasar pada waktu karyawan atau mitra bergabung dan pelatihan rutin dilakukan.

- Pelatihan pengenalan perusahaan yakni memperkenalkan perseroan, jajaran manajemen, aliansi group, sejarah dan lokasi-lokasi kantor berada bagi seluruh karyawan dan mitra.

- Pelatihan Visi, Misi dan Nilai serta Perilaku yang menjadi Jiwa Layanan di dalam Perseroan bagi seluruh karyawan dan mitra.

- Pelatihan tentang pelayanan yang prima, meliputi pelatihan service excellent dan basic customer experience bagi semua front officer seperti mitra, pengemudi, call senter sampai bagian penjualan.

- Pelatihan teradap flow operasi dan pengalaman pemahaman akan pekerjaan.

- Pelatihan Defensive Driving bagi mitra dan pengemudi

\section{Budaya Perusahaan}

Nilai budaya PT WEHA Transfortasi Indonesia TBk mengutamakan 3 prima yaitu:

1. Prima layanan (Excellence in Service)

2. Prima dalam sikap (Excelence in Attitude)

3. Prima dalam Kreativitas (Excellence in Creativity)

Integritas ( Integrity)

- Setiap insan panoramanian harus bertindak dengan integritas (kejujuran, konsisten, komitmen, dan dapat dipercaya) dalam rangka mencapai keunggulan dlam kinerja berdasarkan tuntutan "stakeholders" 
- Unggul dalam pelayanan (Service Excellence)

Fokus pada pelanggan untuk memberikan pelayanan prima dan memastikan produk/ jasa yang dikerjakan dapat memenuhi kebutuhan pelanggan.

- Pembelajaran yang berkelanjutan ( Continuous Learning) Setiap insan panoramanian harus mampu mentransformasikan dirinya secara berkelanjutan, berdasarkan tuntutan yang mampu akan terjadi.

- Kepedulian (Care) Menjaga keselamatan dan kesehatan lingkungan untuk pekerja mitra, masyarakat pada umumnya.

\section{Tata Kelola Perusahaan}

Perinsip tata kelola perusahaan yang baik ( Good Corporate Govermance), yang disingkat menjadi "GCG" merupakan kebutuhan dari perusahaan. Dalam menjalankan roda bisnis, Perusahaan selalu berpedoman pada prinsip "GCG" dalam kegiatan usahanya. Perusahaan memiliki keyakinan yang kuat bahwa dengan penerapan tata kelola perusahaan yang bai akan meningkatkan kinerja perusahaan, bukan hanya untuk saat ini, tapi juga dimasa yang mendatang. Perusahaan juga berkeyakinan bahwa dengan mengimplementasikan prinsip "GCG"dalam semua kegiatan usahanya dapat memperkokoh kepercayaan serta meningkatkan nilai bagi pemegang saham dan pemangku kepentingan lainnya.

\section{Komposisi Karyawan PT WEHA Transportasi Indonesia Tbk,}

Tabel komposisi Karyawan berdasarkan Usia

\begin{tabular}{|l|c|c|c|}
\hline Jenjang Usia & Pria & Wanita & Jumlah \\
\hline Maturist (Umur > 71 & - & - & - \\
\hline Baby Boomer (Umur 55-70 & 24 & 1 & 25 \\
\hline Generation x (Umur 35-54) & 395 & 35 & 430 \\
\hline Generation Y (Umur 21-34) & 245 & 87 & 332 \\
\hline Generation Z (Umur 18-20) & 17 & 16 & 33 \\
\hline
\end{tabular}




\begin{tabular}{|l|c|c|c|}
\hline & & & \\
\hline Total Karyawan & 681 & 139 & 820 \\
\hline
\end{tabular}

Tabel Komposisi Karyawan Berdasarkan Pendidikan

\begin{tabular}{|l|c|c|c|}
\hline Jenjang Pendidikan & Pria & Wanita & Jumlah \\
\hline S2 & 1 & 1 & 2 \\
\hline S1 & 45 & 33 & 78 \\
\hline DI-D3 & 13 & 31 & 44 \\
\hline SMU/ Setara & 461 & 70 & 531 \\
\hline SMP / SD / Setara & 161 & 4 & 165 \\
\hline & & & \\
\hline Jumlah karyawan & $\mathbf{6 8 1}$ & $\mathbf{1 3 9}$ & $\mathbf{8 2 0}$ \\
\hline
\end{tabular}

Tabel Komposisi Karyawan Berdasarkan Jenis Level

\begin{tabular}{|l|c|c|c|}
\hline Jenjang Manajemen & Pria & Wanita & Jumlah \\
\hline Direktur/ Komisaris & 5 & 3 & 8 \\
\hline Wakil Direktur & - & - & - \\
\hline Asisten Wakil Direktur & - & - & - \\
\hline Manager & 9 & 5 & 14 \\
\hline Asisten Manager & - & 2 & 2 \\
\hline Suvervisor & 19 & 13 & 19 \\
\hline Staff & 146 & 73 & 32 \\
\hline Non Staff & 502 & 43 & 545 \\
\hline & & & \\
\hline Jumlah karyawan & $\mathbf{6 8 1}$ & $\mathbf{1 3 9}$ & $\mathbf{8 6 1}$ \\
\hline
\end{tabular}

\section{KESIMPULAN}

Berdasarkan pembahasan dari hasil analisis PT. WEHA TRANSPORTASI INDONESIA Tbk. Selama 2 tahun terakhir yang telah dibahas sebelumya peneliti menarik kesimpulan bahwa PT. WEHA TRANSPORTASI INDONESIA adalah perusahaan yang bergerak di bidang jasa layanan transportasi darat di Indonesia. 
Sumber Daya Manusia PT WEHA Transportasi Indonesia, Tbk menitik beratkan pada pengembangan Sumber Daya Manusia untuk mendapatkan kepuasan pelanggan. Oleh karena itu, mulai dari bagian yang berhubungan langsung dengan pelanggan yakni pengemudi, mitra, call center, Sales Counter, dispatceh, Customer Care sampai dengan bagian yang berfungsi sebagai pendukung berjalannya operasi seperti bagian Tekhnikal, Keuangan, Operasi, Teknologi, Informasi, dan Human Resources. Fokus perusahaan tidak hanya kepada bagian yang berhubungan langsung dengan pelanggan, namun juga memfokuskan pada bagian pendukung pelayanan untuk pelanggan. Berikut 4 pilar Manajemen Manusia PT. WEHA Trasportasi Indonesia Tbk:

1) Rekrutmen

2) Renumerasi

3) Punishment and rewards

4) Pengembangan dan tahapan karir

\section{DAFTAR PUSTAKA}

Annual Repor White horse group 2017 di download juni 2020 http://www.whitehorsegroup.co.id/id/unduh

Annual Repor White horse group 2018 di download juni 2020 http://www.whitehorsegroup.co.id/id/unduh 